\section{UPHOLDING THE INTEGRITY OF ESPORTS TO SUCCESSFULLY AND SAFELY LEGITIMIZE ESPORTS WAGERING}

\section{RYAN P. TOOMEY}

Ryan P. Toomey is an associate attorney at Moadolel Law Firm in Los Angeles, California, where he primarily practices business litigation. Mr. Toomey holds a JD from Whittier Law School (2017) and an LLM in Gaming Law and Regulation from Boyd Law School (2018). The opinions in this article are those of the author and do not reflect Moadolel Law Firm or its clients.

\section{INTRODUCTION}

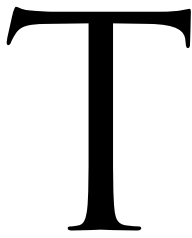

hrough the years, youth have shifted their focus from traditional sports (soccer and baseball) to the ever-evolving world of esports. Esports commonly refers to competitive (professional and amateur) video gaming that is often coordinated by different leagues and tournaments, and where players customarily belong to teams or other "sporting" organizations which are sponsored by various business organizations. ${ }^{1}$ Esports is "a form of sports where the primary aspects of the sport are facilitated by electronic systems; the input of players and teams as well as the output of the esports system are mediated by human-computer interfaces."
Despite negative social stigmas associated with video games, discussed infra, evidence suggests that the activity may be more popular than most believe. In 2013, people around the globe spent approximately 2.4 billion hours watching esports content ${ }^{3}$ and, in 2016, roughly 200 million people played video games in the United States alone. ${ }^{4}$ This global popularity of video games has also allowed the industry to gain ground financially. In 2012, worldwide market revenue from esports reached roughly $\$ 130$ million. ${ }^{5}$ However, in just five years' time, the worldwide market revenue grew to just under $\$ 700$ million and is expected to reach around $\$ 1.5$ billion by $2020,{ }^{6}$ with no indication that its exponential growth will slow anytime soon.

With esports' ever-growing popularity and revenue stream, it is easy to see that many large corporations are looking to get a piece of the esports pie. Of these large companies, casinos and sportsbooks are two major players looking to capitalize on esports and esports betting. However, before these businesses will dive in head first, several issues must be addressed to legitimize the industry for investors and consumers alike.

Video game industry leaders must tackle internal problems before sportsbooks and casinos will buy into the hype. Perhaps the most significant issue regarding esports is the lack of a universal regulatory body. Presently, there is little to no regulation of organized tournament play in the esports sphere. With individual publishers controlling the intellectual property of their respective games and platforms, opportunists, such as match fixers, have filled gaps in the market and taken advantage of players and publishers in order to gain financially. Unsavory conduct including match fixing and doping have proven to be significant contributors to the integrity issues faced by the esports industry. Therefore, the industry as a whole must offer greater safeguards to ensure integrity and legitimacy if it wishes to grow to mainstream levels such as the NFL and other traditional sports.
Keywords: esports, skins betting, sports betting, match fixing, doping, esports integrity

DOI: 10.1089/glr2.2019.23112 (C) 2019 Mary Ann Liebert, Inc.

${ }^{1}$ Juho Hamari and Max Sjöblom, What Is Esports and Why Do People Watch It?, 27 InTERNEt Res. 211, 211 (2017).

${ }^{2} I d$.
${ }^{3}$ Times Spent Watching Esports Video Worldwide in 2012, 2013, and 2018 (in Billion Hours), HIS 1 (2014).

${ }^{4}$ Number of Video Gamers Worldwide in 2016, by Region (in Millions), NEwzoo 1 (2016)

${ }^{5}$ Esports Market Revenue Worldwide from 2012 to 2020 (in Million U.S. Dollars), ESPORTS MARKET WorLdWIDE 1, 7 (2017).

${ }^{6} I d$. 


\section{REGULATION}

In 2017, the top ten highest-earning video game publishers included NetDragon Websoft (\$238 million), Nintendo (\$262 million), NCSoft (\$288 million), Activision Blizzard (\$966 million), Electronic Arts (\$967 million), Time Warner ( $\$ 1.7$ billion), Natease Games ( $\$ 1.7$ billion), Sony Corporation ( $\$ 2.6$ billion), Tencent Holdings ( $\$ 5.9$ billion), and Microsoft Corporation (\$21 billion). ${ }^{7}$ Each publisher creates its own line of games with its own style of game play and its own set of rules and regulations. The games vary from sports games (Madden, FIFA, and the NBA 2K series) to massive multiplayer online games (MMOs) (League of Legends and World of Warcraft), role playing games (RPGs) (Fallout and Diablo), first-person shooters (FPS) (Call of Duty and Rainbow Six), and more. Adding to the complexity of the issue, the games can be played on different consoles (PlayStation, Xbox, and PC) with each console providing a different gameplay experience. Though some rules and regulations may be similar, and certain games may be played on a variety of consoles, no universal regulatory system exists to ensure that integrity is upheld in the esports industry. The integrity of a sport - in its governing institutions, competitions, participants, and each of its contests - has rightly become recognized as a fundamental pillar upon which everything else in the sport is built and relies. ${ }^{8}$ It is vital for the esports industry to pursue the highest standards of integrity, otherwise it will be difficult to sustain growth in new markets, including the casino and sports betting industries. To achieve such high standards of integrity, esports must take proactive steps to guarantee that misconduct does not plague the industry.

\section{WAGERING ON ESPORTS}

Wagering on the outcomes of esports matches and tournaments has grown substantially over the years.
According to the website Statista, the estimated total amount wagered on esports on cash gambling sites worldwide in 2016 was roughly \$594 million. ${ }^{9}$ Grove and $\mathrm{Krejcik}^{10}$ have categorized three prominent types of esports gambling products: sportsbook betting, fantasy esports, and skins betting. ${ }^{11}$

\section{A. Sportsbook betting}

Sportsbook-style betting is similar to the traditional conceptualization of sports betting. ${ }^{12}$ In sportsbook-style betting, the bettor is merely a spectator of a match played between two esports teams and places a wager on the outcome of the match or other propositions that occur throughout the game, similar to placing a wager on the outcome of a football game. Bettors may place a variety of different bets on matches played throughout the world.

\section{B. Fantasy esports}

Fantasy esports are contests where participants compete for cash or prizes based on a scoring system that takes into account the accumulated statistics of professional athletes chosen as a part of a fantasy team. ${ }^{13}$ In fantasy esports, points are given based on the statistics a particular player generates in the course of a single game or competition, or throughout a full season, and the participant with the highest cumulative point total wins cash or prizes. ${ }^{14}$ Traditionally, an auction involving a bidding process allocates athletes among participants in the fantasy league. ${ }^{15}$ Over the years however, a modified auction evolved to allocate players by determining the value of each professional player, decided before the competition, and allowing multiple participants to select the same players. ${ }^{16}$ Modernly, players are allocated in a "draft," similar to the way the sport itself drafts players. ${ }^{17}$ These traditional fantasy esports competitions run for the length of the particular sport's season

\footnotetext{
${ }^{7}$ Alex Gibson, Top 10 Highest Earning Video Game Publishers of 2017's Fiscal Year, Twinfinite (Aug. 18, 2017), http://twinfinite.net/2017/08/10-highest-earningvideo-game-publisher/10/

${ }^{8}$ Adam Brickell, Addressing Integrity and Regulatory Risk in Esports: The Responsibility of the Whole Esports Community, 21 Gaming L. Rev. 603, 603 (2017).

${ }^{9}$ Estimated Total Amount Wagered on Esports on Cash Gambling Sites Worldwide in 2016, by Product Type (in Million U.S. Dollars), STATISTA 1 (2018).

${ }^{10}$ Chris Grove \& Adam Krejcik, eSports Betting: It's Real, and Bigger Than You Think, EILERS RESEARCH (Aug. 19, 2015).

${ }^{11}$ John T. Holden, Ryan M. Rodenberg, and Anastasios Kaburakis, Esports Corruption: Gambling, Doping, and Global Governance, 32 MD. J. OF INT. LaW 236, 249 (2017).
} 
or for the duration of a tournament. ${ }^{18}$ Even more recently, many fantasy esports competitions, known as daily fantasy sports (DFS), last for less than the traditional fantasy sports leagues. DFS allows participants to pay an entry fee, select players, enter into a contest, and potentially receive prize money daily. ${ }^{19}$

\section{Skins betting}

Betting using in-game items (skins) as currency is the largest segment of the esports betting market and is almost entirely unregulated. ${ }^{20}$ Skins betting can occur on a match in which the bettor is not a participant or can occur between players participating in the match to be bet on. This segment of esports betting is primarily confined to the games Counter-Strike: Global Offensive (CS:GO) and Defense of the Ancients (DOTA) due to in-game technology that allows players to transfer in-game items in marketplaces external to the games themselves. ${ }^{21}$ In August of 2012, the popular publisher Valve Corporation released CS: GO, a multiplayer FPS, where players are separated into two teams, a terrorist team and an antiterrorism team, that compete against each other to achieve certain objectives. ${ }^{22}$ CS:GO was initially unsuccessful but soon after its release, Valve introduced decorative virtual weapons (skins) that participants can acquire through gameplay and sell outside the platform with third-party companies. ${ }^{23}$ Soon after the introduction of skins, CS:GO boomed in popularity. Roughly four years after its initial release, Valve sold 21 million copies of the game and made $\$ 567$ million in total revenue. ${ }^{24}$ With CS:GO's rapid growth and booming popularity, third-party companies like CS:GO Lounge have created spaces where people can wager their skins on individual matches and exchange the skins for real-life currency or use the skins to play gambling games (e.g., coin flip) on other third-party sites.
According to Eilers \& Krejcik Gaming, more than three million people wagered $\$ 2.3$ billion worth of skins on the outcome of esports matches in $2015 .^{25}$ Despite the large handle produced by these wagers, the ultimate setback to skins betting is that it is virtually unregulated. Efforts have been made to regulate this corner of the esports market but have fallen short of successful regulation. On October 5, 2016, the state of Washington's Gaming Commission notified Valve that it must immediately stop allowing the transfer of skins for gambling activities through its Steam platform. ${ }^{26}$ In response, Valve issued a cease and desist letter to 23 different third-party CS:GO gambling sites to cease any gambling associated with games played on the Steam platform. ${ }^{27}$ Many of the named sites ceased operations; however, with every site that ceased operations, another CS:GO gambling site would open its doors to customers seeking to continue their activity. So far, attempts at regulation have only resulted in a constant battle of cat and mouse with the mouse consistently emerging as the victor.

With little to no regulations, modern technology used by games such as CS:GO and third-party gambling sites has allowed skins wagering to slip through the cracks of regulation. This lapse in oversight has allowed opportunists to take advantage of players and consumers by engaging in corrupt conduct such as match fixing and doping.

\section{Match fixing}

As evidenced by articles over the years, professional sports like baseball, soccer, and boxing, have dealt with the issues related to match fixing. ${ }^{28}$ With esports' booming popularity around the world, match fixing is arguably one of the biggest struggles the industry faces. What makes match fixing more challenging to

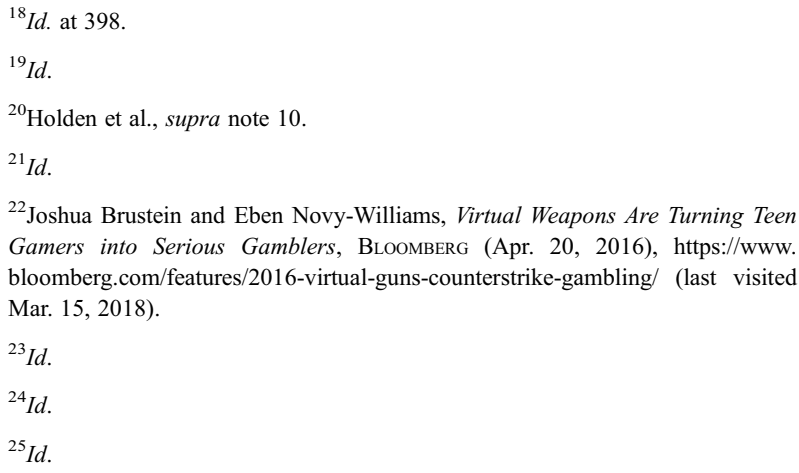

\footnotetext{
${ }^{26}$ Sam Cooke, Washington State Gambling Commission Orders Valve to Stop All Skins Transfers Related to Gambling, ESPORTS INSIDER (Oct. 6, 2016).

${ }^{27}$ Matthew Lui, A Year After Valve's Cease and Desist Letter, Inside the End of One Skin Betting Site, The Lines (July 20, 2017).

${ }^{28}$ Choe Sang-Hun, South Korea Charges 21 with Match Fixing, N.Y. TImes (Nov. 7, 2016), https://www.nytimes.com/2016/11/08/sports/baseball/south-korea-matchfixing.html; Tales Azzoni, 6-Year Bans Sought for 36 Players for Match-Fixing in Spain, WASH. Post (Feb. 14, 2018), https://www.washingtonpost.com/sports/ dcunited/bans-sought-for-30-plus-players-for-match-fixing-in-spain/2018/02/14/ $538 \mathrm{e} 3 \mathrm{ce} 8-116 \mathrm{c}-11 \mathrm{e} 8$-a68c-e9374188170e_story.html?utm_term $=.818046 \mathrm{dca} 79 \mathrm{~d}$; Jamie Gordon, Boxing Could Be Banned from 2020 Olympics Due to Worries over Match-Fixing, THE Sun (Feb. 4, 2018), https://www.thesun.co.uk/sport/boxing/ 5497258/boxing-2020-olympics-tokyo-ban/.
} 
identify in this virtual world is the anonymity associated with competitive video game play. Players do not use their legal names, nor can players determine whether other players are who they say they are. Instead, players choose usernames to identify themselves while playing the game. Anonymity is a key attribute in esports partly because it allows the player to assume a different identity and escape the problems and hardships associated with the real world. While playing games under this new identity, the player can be an expert huntsman or a champion race-car driver, giving the individual a sense of worth and accomplishment they may not attain in real-world activities. However, anonymity is a double-edged sword. With the username as the only identification of the player, players can easily engage in unsavory behavior by swapping players of different talent levels throughout the game. Professionals are able play under various usernames undetected, causing bettors and opponents to believe the player associated with the username is either better or worse than what is perceived, essentially manipulating the betting market and controlling the outcome of the match. This has created a fertile ground for illegal betting as some players risk their reputation and career to gain high-value items from other players. ${ }^{29}$

Arguably the most prominent scandal in esports unfolded in October 2015, when South Korean investigators arrested 12 people in association with five fixed StarCraft 2 (SC2) matches. ${ }^{30}$ Exploiting the illegal betting market, orchestrators of the scheme paid three SC2 players to throw matches allowing them to win roughly $\$ 37,000$ off the matches. ${ }^{31}$ In 2015 , game developer and competition sponsor Valve permanently banned $21 \mathrm{CS}$ :GO players accused of match fixing in competitive matches from their professional gaming events. ${ }^{32} \mathrm{CS}$ :GO is not the only game facing these problems; DOTA 2 has also been susceptible to match fixing issues. In 2013, a Russian player named Aleksey "Solo" Berezin bet against his team in a major event and won $\$ 322 .{ }^{33}$ A similar scandal came into the spotlight in 2014 after MSI Evolution and Minseski, two popular DOTA 2 teams from the Philippines, were accused of match fixing. ${ }^{34}$ The teams threw the matches they were anticipated to win to qualify for a playoff spot in exchange for money. ${ }^{35}$

Although publishers and league organizers have attempted to infiltrate the various match fixing schemes at the professional level, the assumption that these types of schemes do not occur at all levels of play is naïve. Third-party gambling sites allow individuals to wager on virtually any game with no safeguards put in place to verify who the player actually is. To stop match fixing entirely will be nearly impossible however, the creation of a single regulatory body will be a giant first step in legitimizing esports. Implementation of a single regulatory body will allow for consistency throughout all games and platforms thus, filling holes in the current rules and regulations.

Some publishers (EA Sports and Ubisoft) have taken their own steps to prevent cheating in their games and to protect their players. These publishers have partnered with companies like GameBlocks to help prevent cheating. ${ }^{36}$ GameBlocks provides video game publishers with powerful and intuitive middleware that allows them to combat cheating, manage gameplay, and monitor their titles' performance from macro to granular levels. ${ }^{37}$ GameBlocks' FairFight software is an automated cheat detection and suppression system that uses two overlapping and mutually supportive methods to identify cheaters: algorithmic analysis of player statistics and server-side cheat detection. ${ }^{38}$ FairFight uses algorithmic models to evaluate gameplay against multiple statistical markers to identify cheating as it happens and cross-checks this data using objective server-side tools. ${ }^{39}$ By using software like FairFight, publishers are able to warn, suspend, and ban players from the platform who engage in unsavory conduct. ${ }^{40}$ Casinos, sportsbooks and gambling

\footnotetext{
${ }^{29}$ Aurangzeb Durrani, Match-Fixing Comes to the World of E-sports, TECH CRUNCH (Apr. 23, 2016), https://techcrunch.com/2016/04/23/match-fixing-comes-to-theworld-of-e-sports/.

${ }^{30}$ Holden et al., supra note 10 .

${ }^{31} I d$.

${ }^{32}$ Durrani, supra note 28.

${ }^{33} I d$.

${ }^{34} I d$.
}

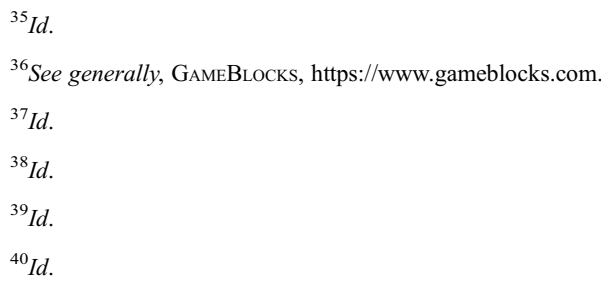


regulators may be more willing to bring esports betting into their establishments and jurisdictions knowing safeguards like GameBlocks' FairFight software have been put in place; however, publishers must also implement their own internal protective measures if they hope to stop match fixing for good. When thousands, potentially millions of dollars are on the line, bettors will seek insurance that the matches they are wagering on are legitimate.

\section{Doping}

While corruption has plagued both the esports industry and its associated gambling market, the lack of central governance implicitly condones the use of performance-enhancing drugs. ${ }^{41}$ Just as in traditional sports like baseball and cycling, the appeal of gaining a competitive edge is clear, especially when potentially millions of dollars are at stake. ${ }^{42}$ Similar to blood doping in cycling, doping benefits esports players by allowing them to train longer and harder. ${ }^{43}$ An anonymous source told ESPN's Outside the Lines that he had sold performance-enhancing drugs to "half" of the top 20 players in gaming tournaments he had competed at in the past. ${ }^{44}$ Brandon Harris, a law student and gamer at the University of New Hampshire who writes on legal issues in esports, says it is common to see a range of stimulants used during competitions, "and if you're using a broad definition of doping - i.e., 'taking any substance in an attempt to improve gameplay' - the use would be extremely widespread. Caffeine, energy drinks, ginseng supplements, all sorts of over-the-counter stuff is heavily and excessively used." 45

While some players use over-the-counter medications and supplements in the tournament setting, one of the most used drugs in esports is Adderall, "a medication used to treat attention-deficit/hyperactivity disorder (ADHD)." ${ }^{46}$ Even though Adderall has legitimate uses in other circumstances, it can help video-game players by giving them an extra boost during gameplay. ${ }^{47}$ In esports, how quickly you can read your competition's moves and react is vital; it is about being able to focus on the game at hand and then calmly and swiftly maneuver to victory. ${ }^{48}$ Adderall enables esports players to play longer, more consistently, and with greater ability. ${ }^{49}$ Some opponents of Adderall's performance enhancing effects on video game players suggest that the drug is "more effective at correcting deficits than "enhancing performance," it does not actually help players play at a more advanced level. ${ }^{51}$ However, research suggests that even if Adderall does not have a direct effect on the brain, the placebo effect is strong enough to have a meaningful impact on players and therefore, enhances gameplay. ${ }^{52}$ Ultimately, Adderall and other like drugs continue to be a problem area in esports, which raises questions related to the legitimacy and integrity of the esports community as a whole.

Accusations of doping have plagued esports since professional Counter-Strike player Kory "Semphis" Friesen admitted in a 2015 interview that he and his Cloud9 teammates had taken Adderall before a tournament in Katowice, Poland. ${ }^{53}$ In response to Mr. Friesen's claim, the Electronic Sports League (ESL), which organizes many of the world's biggest esports tournaments, announced stricter anti-doping measures for future events. ${ }^{54}$ Stricter anti-doping is a great start to combating doping in esports; however, the battle against doping is far from over. Apart from ESL, which specializes in League of Legends (LOL) and Counter-Strike events, esports teams

\footnotetext{
${ }^{41}$ Holden et al., supra note 10.

${ }^{42}$ Kevin Loria, Some Competitive Video Gamers Are Abusing Drugs to Get an Edge, Bus. InSIDER (Jan. 15, 2016), http://www.businessinsider.com/esportsdoping-scandal-investigated-by-espns-otl-2016-1.

${ }^{43}$ Hal Hodson, Esports: Doping Is Rampant, Industry Insider Claims, New SCIENTIST (Aug. 13, 2014), https://www.newscientist.com/article/dn26051-esportsdoping-is-rampant-industry-insider-claims/.

${ }^{44} I d$.

${ }^{45} I d$.

${ }^{46}$ Adderall and Adderall XR (amphetamines) Information, U.S. Dep'T. OF HEALth \& Hum. Services, https://www.fda.gov/Drugs/DrugSafety/PostmarketDrugSafety InformationforPatientsandProviders/ucm111441.htm (last visited Mar. 15, 2018).
}

${ }^{47}$ Loria, supra note 41.

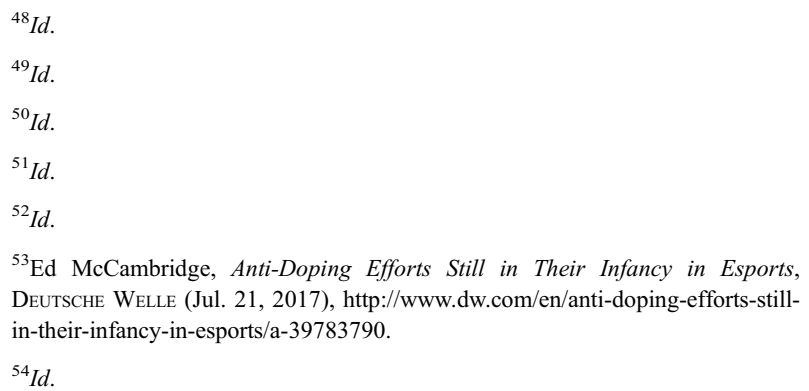


are generally self-regulating. ${ }^{55}$ Additionally, doping regulation is nonexistent in matches that occur outside organized play and tournament play. As some teams may be tempted to use various drugs in order to win, self-regulation will no doubt lead to bigger problems. Implementation of a regulatory body whose purpose is to ensure esports athletes remain drug free would curb this problem and would further legitimize esports.

Without uniform regulation, doping will continue to plague the esports community. Doping controversy will no doubt cause casinos, sportsbooks, and gaming jurisdictions to shy away from engaging in business with esports. The mission of the Nevada Gaming Control Board, a regulatory body commonly viewed as the gold standard of gaming regulation, aims to "govern Nevada's gaming industry through strict regulation of all persons, locations, practices, associations and related activities. We protect the integrity and stability of the industry through our investigative and licensing practices, and we enforce laws and regulations while holding gaming licensees to high standards." ${ }^{56}$ Without some type of stricter uniform regulation, it will be virtually impossible for the esports industry to reach the level of legitimacy required for casinos and sportsbooks to successfully expand esports betting in jurisdictions outside of Nevada.

\section{MEASURES TAKEN TO PROTECT THE INTEGRITY OF ESPORTS}

Notwithstanding the negativity surrounding the esports industry, some organizations are doing their best to ensure the longevity and prosperity of esports. Two of these organizations are the Esports Integrity Coalition (ESIC) and the World Esports Association (WESA).

\section{A. Esports Integrity Coalition}

The Esports Integrity Coalition is a nonprofit members association established in 2015 by key esports stakeholders to deal with issues of common interest - in particular, the threat that match manipulation, betting fraud, and other integrity challenges posed to esports. ${ }^{57}$ ESIC is as close to a uniform regulatory body as the esports community has. Under ESIC, its members, no matter the publisher or game, can follow a uniform set of guidelines to ensure integrity in its gameplay and competitions. ${ }^{58}$ ESIC's guidelines contain an integrity program which includes a code of conduct, code of ethics, anti-corruption code, anti-doping code, and a list of all banned substances. ${ }^{59}$

According to ESIC, the most significant threats to esports are (1) cheating to win using software cheats, (2) online attacks to slow or disable an opponent, (3) match fixing, and (4) doping. ${ }^{60}$ ESIC handles these threats by publishing for all members, its code of conduct, focused on cheating to win; the anti-corruption code, focused on match fixing; and its anti-doping policy ${ }^{61}$ It works with each member to implement these codes into their businesses in the most appropriate way, ${ }^{62}$ creating a common regulatory framework for handling threats to integrity. ${ }^{63}$ Common definitions and a unified disciplinary procedure bind the codes together. ${ }^{64}$ Additionally, ESIC provides online tutorials to educate players across the esports world, which provides an easily accessible method for distributing necessary knowledge to the community. ${ }^{65}$ Further, over the last year ESIC has provided live, face-toface, anti-corruption education to more than 400 professional players across CS:GO, DOTA 2, LOL, and SC2. Although reaching all esports players using face-to-face methods is extremely expensive, time-consuming, and inevitably misses the vast constituency that does not play in major

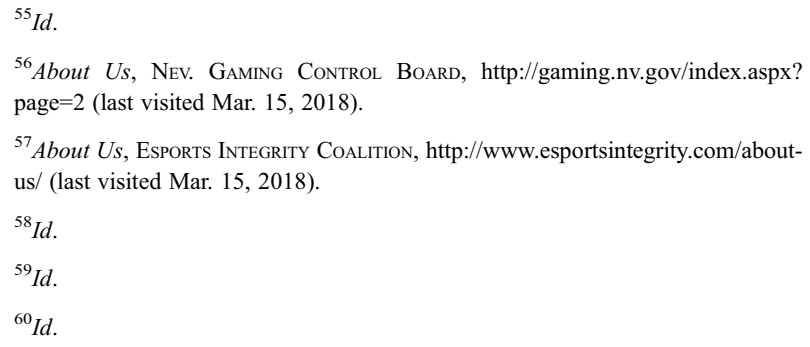

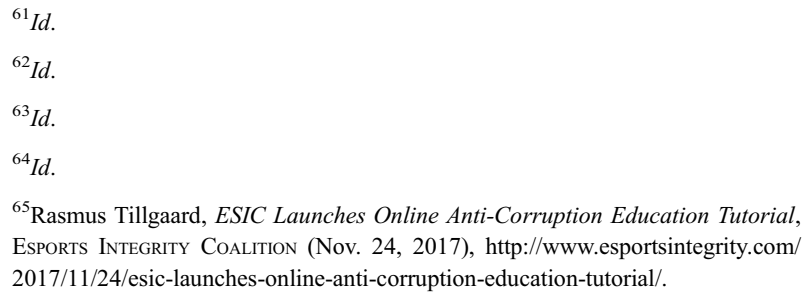


LAN events, ${ }^{66}$ ESIC can continue to reach and educate players worldwide through online tutorials and other more cost-efficient methods.

ESIC differs from other organizations because it creates a regulatory framework for esports, while taking proactive steps to ensure the information reaches the community effectively. ESIC attempts to advance the esports industry by shifting its education system from a passive approach to a more proactive approach that provides up-to-date information on problems and regulations within the industry.

\section{B. World Esports Association}

Similar to ESIC, the World Esports Association is an open and inclusive organization that will further professionalize esports by introducing elements of player representation, standardized regulations, and revenue shares for teams. "WF "WES seeks to create predictable schedules for fans, players, organizers, and broadcasters, and for the first time bring all stakeholders to the discussion table. ${ }^{, 68}$ For esports to become a legitimate business in which legal gambling corporations will invest, publishers, players, and organizations like ESIC and WESA must work together to ensure cheating, doping, and other undesirable activities have no place in the esports community.

Though ESIC and WESA have taken steps to uphold the integrity of esports, members of these organizations are also internal members of the esports community, which may create other problems. Permitting community members to regulate and monitor the activities in esports opens the door to potential corruption, bribery, and additional internal struggles. ${ }^{69}$ It is important that the esports industry address these potential problems when creating a uniform regulatory body. The esports industry would be wise to include local, state, federal, and other international governing bodies to help uphold the highest of integrity standards. The issues that esports faces today are no dif- ferent than the issues that have faced traditional sports for decades. Together, the esports industry and the various governing bodies can develop policies, regulations, oversight and enforcement to allow leagues, developers, players, and bettors to engage in their respective activities knowing the abovedescribed problems will not be an issue.

\section{v. CONCLUSION}

This growing industry must overcome many hurdles if it hopes to have casinos, sportsbooks, and regulators engage in business and invest in its untapped potential. The anonymity of video game play poses two issues: on one side, anonymity gives the player the opportunity to escape the real world and excel in something they love, while on the other hand, anonymity presents an opportunity for people to take advantage of the system for their financial gain and benefit.

There is no solve-all answer that will rectify the problems facing esports. However, a proactive approach is critical to targeting the problems within esports. As more members of the esports industry are educated in match fixing and doping, and with the help of organizations like ESIC and WESA, esports has a bright future ahead of it. Though technology continues to advance at a rapid pace, so does the opportunity for increased security within the esports space. Technological advancements should not be a deterrent for regulation but, instead, should invite the opportunity for esports to continue to grow and to protect all those involved in the industry. Sports like baseball, football, boxing, and cycling have gone through the same struggles the esports world faces today. It would be wise for the esports industry to take a page out of history and learn from the mistakes of these established sports entities. There is no doubt that esports will excel for years to come if it approaches these problems systematically, proactively, and with a larger plan rather than a "learn as you go" approach.
${ }^{66}$ Local area network (LAN) definition: "Computers. a system for linking personal
computers and workstations with each other in order to share data, devices, pro-
grams, etc.: usually confined to one office, building or home." DictionARY.COM,
http://www.dictionary.com/browse/lan (last visited Mar. 15, 2018).
${ }^{67}$ About us, WORLD ESPORTS AsSOCIATION, http://www.wesa.gg (last visited Mar. 15,
2018 ).
${ }^{68}$ Id.
${ }^{69}$ This scenario has been exposed as a problem in sports organizations throughout
the world. On September 29,2017 , the college basketball world was turned upside down when FBI investigations revealed mass corruption, bribery, and wire fraud involving some of the sport's top programs. In 2016, congressional investigators concluded that at least a half-dozen top National Football League (NFL) health officials waged an improper, behind-the-scenes campaign in 2015 to influence a major U.S. government research study on football and brain disease. Steve Fainaru and Mark Fainaru-Wada, Congressional Report Says NFL Waged Improper Campaign to Influence Government Study, ESPN (May 24, 2016), http://www. espn.com/espn/otl/story/_id/15667689/congressional-report-finds-nfl-improperlyintervened-brain-research-cost-taxpayers-16-million. 